INTERNACIONAL

\title{
Cambio de foco en la priorización de casos de la Corte Penal Internacional: Los delitos ambientales
}

\author{
Changing the scope in the prioritization of the International Criminal Court: \\ Environmental crimes
}

Sebastián SMART

University College, Londres

\begin{abstract}
RESUMEN El 15 de septiembre de 2016, la Oficina del Fiscal de la Corte Penal Internacional emitió un documento sobre priorización y selección de casos a ser investigados que tuvo gran repercusión mediática en grupos defensores del medioambiente. Dicha repercusión se basó principalmente en los párrafos 40 y 41 del documento, que abren la puerta a la focalización de investigación y persecución de crímenes ambientales en el contexto de la CPI. A pesar del impacto mediático, la doctrina no ha elaborado las potencialidades y limitaciones de esta nueva herramienta. Bajo un análisis del documento de priorización, este trabajo busca contribuir a dicha discusión, hasta llegar a la conclusión de que si bien esta nueva política no significa que se cambia la competencia de la Corte, se trata de un importante cambio de foco que puede avanzar en evitar la impunidad con la que la comunidad internacional ha tratado dichos crímenes.
\end{abstract}

PALABRAS CLAVE Corte Penal Internacional, delitos ambientales, defensores de derechos humanos.

ABSTRACT On September 15, 2016, the Office of the Prosecutor of the International Criminal Court issued a document on prioritization and case selection of cases to investigate that had great media impact, mainly on groups that defend the environment. This impact was primarily based on paragraphs 40 and 41 of the document, which leaves an open door to investigate and prosecute environmental crimes in the context of the ICC. Despite the media impact, the doctrine has not elaborated the potentialities and limitations of this new tool. Under an analysis of the prioritization document, this paper seeks to contribute to this discussion, concluding that although this new policy does not mean that the Court's competence is been modified, it is an important change of focus that can contribute to avoid the current impunity existent in such crimes. 
KEYWORDS International Criminal Court, environmental crimes, human rights defenders.

\section{Introducción}

Desde que la Corte Penal Internacional tiene jurisdicción, ésta ha investigado principalmente crímenes de lesa humanidad y crímenes de guerra, por lo que ha dejado de lado la investigación de crímenes que tendrían similar relevancia en materia de violaciones del derecho internacional de los derechos humanos, dentro de ellos, los delitos económicos, sociales y culturales, los delitos ambientales y los delitos que se cometen contra defensores del medioambiente ${ }^{1}$. En este sentido, la Corte ha evadido tanto la relación que existe entre los principios y obligaciones generales del derecho internacional de los derechos humanos y del medioambiente (Naciones Unidas, 1968 $)^{2}$ como la profundización y elaboración de dicha interconexión realizada por una vasta jurisprudencia internacional (Sands y Peel, 2012: 773-798).

Aunque se entienden los factores históricos y políticos que explican la focalización de la Corte, no deja de llamar la atención que las víctimas de ciertas violaciones de derechos económicos, sociales y culturales consagradas como crímenes graves en un contexto de guerra queden desprotegidas en contextos de paz ${ }^{3}$. Con ello se genera un marco de impunidad penal por las graves violaciones a derechos humanos que se relacionan, dentro de otros, con el medioambiente (Drumbl, 2000; Skogly, 2001). Con el fin de comenzar a dar solución a dichas violaciones, el 15 de septiembre de 2016, la Fiscalía de la Corte publicó un nuevo documento de priorización y selección de casos que, dentro de otros, focaliza la selección de casos que han sido históricamente desatendidos, entre ellos la destrucción del medioambiente, la explotación ilegal de los recursos naturales y la desposesión ilegal de tierras (Corte Penal Internacional, 2016: párrafos 40-41), lo que deja una ventana abierta para conocer los delitos medioambientales.

1. Todos los casos cerrados en la Corte (cinco casos) tratan sobre crímenes de lesa humanidad y dos de ellos tratan también sobre casos de crímenes de guerra, ninguno de ellos referidos a la destrucción ambiental como forma de crimen de guerra. Por otra parte, ninguno de los diez casos que actualmente se encuentran bajo investigación hacen referencia a crímenes relacionados con violaciones de defensores de las tierras o del medioambiente. Ver más información en el sitio de la Corte Penal Internacional, disponible en http://bit.ly/2cXvC5N.

2. Véase el vigésimo tercer período de sesiones de la Asamblea General de las Naciones Unidas, resolución 2.398 (XXIII), adoptada el 3 de diciembre de 1968. En el preámbulo se declaran los principios de protección y prevención ambiental para la presente y futuras generaciones. Principios que también se han consagrado a nivel regional. Ver, por ejemplo, el artículo 11 del Protocolo de San Salvador en Organización de Estados Americanos (1988).

3. El Estatuto de Roma consagra el delito de destrucción ambiental, experimentos médicos en personas o derecho a la alimentación. Véase Naciones Unidas (1998), artículos 8.2.b.iv, 8.2.b.x y 8.2.b.xxv. 
Se trata de una transformación novedosa de la Corte cuyo potencial efecto en materia de protección y reparación de derechos ambientales y de violaciones de derechos de defensores de derechos humanos y del medioambiente ha sido escasamente desarrollado por la doctrina. La novedad de este trabajo recae, pues, precisamente en iniciar la discusión sobre el potencial efecto de dicho documento de priorización. Para ello, en la primera parte de este trabajo se tratará sobre los aspectos novedosos y los pasos metodológicos utilizados por la Fiscalía para seleccionar casos, en la segunda parte se analizan tanto el potencial impacto como las limitaciones del documento de priorización, mientras que en la tercera parte se elaboran las formas que podría utilizar la Corte para tratar los delitos ambientales y aquellos que se cometen contra defensores de derechos humanos y del medioambiente. El trabajo concluye que la transformación en la priorización y selección de casos no significa que se amplía la competencia de la Corte, sino simplemente - pero no menos importante- una nueva forma de seleccionar casos a investigar ampliando la posibilidad para que la Corte se enfoque en violaciones a derechos humanos que ocurren, por ejemplo, en el contexto extractivista que predomina en América Latina.

\section{El documento de priorización}

El documento de priorización propuesto por la Fiscalía resume las guías para el ejercicio discrecional que ejerce dicho órgano de la Corte en la selección y priorización de casos en una situación grave o casos graves que ocurren en distintas situaciones. Es un documento que autorreconoce sus limitaciones, ya que se basa en la incapacidad práctica de la Corte de investigar y perseguir todos y cada uno de los crímenes cometidos en una situación específica (Corte Penal Internacional, 2016: párrafo 11). Es, pues, un mecanismo para que la Fiscalía determine la relevancia de los casos a ser investigados $y$, aunque el esperado criterio es que éste evolucione en concordancia con la jurisprudencia de la Corte (Corte Penal Internacional, 2016: párrafos 4-5), lo esperable sería justamente lo contrario, es decir, que la jurisprudencia de la Corte evolucione de acuerdo con la ruta propuesta por la Fiscalía. Aunque la decisión de la Corte no signifique la consagración de nuevos derechos, ni mucho menos la ampliación de su competencia, es un pequeño paso que permite pensar en la posibilidad de futura jurisprudencia en materia de delitos ambientales en virtud de la actual consagración de delitos establecidos en el Estatuto de Roma.

En términos concretos, la nueva política de la Fiscalía propone seleccionar casos de acuerdo con principios, criterios legales y características específicas de los crímenes. El primer filtro para dicha selección se basa entonces en los principios de independencia, imparcialidad y objetividad ${ }^{4}$. Sin embargo, el Estatuto de Roma reconoce

4. El principio de independencia señala que la Fiscalía debe actuar independiente de las instrucciones 
que la Corte debe también observar — para la selección de casos- su jurisdicción ${ }^{5}$ y seguir los criterios de complementariedad y gravedad para determinar su competencia $^{6}$. Además, al menos desde el año 2007, la Corte reconoce el interés de las víctimas para obtener justicia y su protección en la selección de los casos a ser investigados (Corte Penal Internacional, 2007). Por último, como aspecto novedoso de las regulaciones recientes de la Fiscalía, la Corte se basará en las características específicas del caso que dicen relación con la gravedad de los crímenes, el grado de responsabilidad del autor y las acusaciones aplicables al caso en concreto.

Lo novedoso del documento recae entonces en la metodología que utilizará la Fiscalía para seleccionar los casos a investigar. En este sentido, el documento emitido por la Fiscalía viene a complementar la guía adoptada el año 2013, que establece el mecanismo para definir las situaciones prioritarias y que se basan en los ya descritos principios y reglas legales (Corte Penal Internacional, 2013b). Tomando en consideración dicha metodología, la Fiscalía establece tres criterios para la selección de casos.

El primero es el criterio de gravedad de los crímenes. Para determinar la gravedad, la Fiscalía establece reglas específicas que permiten evaluar la escala, naturaleza, forma de comisión e impacto de los crímenes. La escala sería medida, dentro de otros parámetros, por el número de víctimas directas e indirectas, la extensión del daño (particularmente daño físico y psicológico de las víctimas y sus familiares) y la intensidad geográfica y temporal de los crímenes (Corte Penal Internacional, 2016: párrafo 38). La naturaleza de los crímenes se refiere a los elementos objetivos del delito, es

de cualquier agente externo, en este sentido, la Fiscalía no está sujeta a las comunicaciones de Estados, del Consejo de Seguridad de las Naciones Unidas o de comunicaciones individuales (Corte Penal Internacional, 2013a: capítulo 2, sección 2). El principio de imparcialidad se refiere a la obligación de la Fiscalía de investigar a todos los grupos o partes que se ven involucrados en una particular situación de gravedad, sin hacer distinción de Estados ni de individuos (Corte Penal Internacional, 2013a: capítulo 2, sección 6). Por último, el principio de objetividad se refiere a que en el proceso de selección de casos se debe atender a la información y evidencia disponible y accesible.

5. Para determinar la jurisdicción de la Corte se deben observar los principios de nacionalidad y territorialidad y las limitaciones impuestas a ellos por el artículo 12 del Estatuto de Roma. El principio de territorialidad permite a la Corte investigar crímenes cometidos en un Estado parte, aunque estos hayan sido cometidos por una persona que tenga la nacionalidad de un Estado que no es parte del Estatuto de Roma. El principio de nacionalidad señala que podrá investigarse la comisión de delitos cometidos por quien tenga la nacionalidad de un Estado parte, aunque éstos hayan sido cometidos en un territorio de un Estado que no es parte del Estatuto de Roma. La excepción a los principios de territorialidad y nacionalidad está expresada en el artículo 13 del Estatuto de Roma.

6. En este sentido, la Corte observará si el Estado parte está ya investigando los mismos crímenes y las mismas conductas, además de observar si los procedimientos locales tienen la capacidad de realizar dicha investigación sin vicios. En cuanto a la gravedad, la Corte hace un examen cualitativo y cuantitativo de la escala, naturaleza, forma de comisión e impacto de los crímenes (Corte Penal Internacional, 2013b: párrafos 59-66). 
decir, si ocasionó muerte, violación o crímenes sexuales, crímenes contra niños, persecución o imposición de formas de vida a un grupo de personas determinado (Corte Penal Internacional, 2016: párrafo 39). La forma de comisión se refiere a los métodos empleados para cometer el delito, dependiendo de si ellos fueron sistemáticos, organizados, en abuso de poder, dentro de otros parámetros (Corte Penal Internacional, 2016: párrafo 40). La Fiscalía también tomará en consideración el impacto de los crímenes, según la vulnerabilidad de las víctimas, el terror instalado o el daño social, económico o ambiental infligido a las comunidades (Corte Penal Internacional, 2013: párrafo 41).

El segundo criterio es el de responsabilidad de los autores. Tomando en consideración este criterio, la Fiscalía ha determinado que lo primero que hará será enfocarse en la identificación de las organizaciones (incluidas sus estructuras) y en los individuos responsables por la comisión de los crímenes. El foco se pondrá en mandos altos y medios de las organizaciones, a menos que alguna persona, ejerciendo cargos menores, haya cometido una actuación particularmente grave o notoria. Se señala, además, que la responsabilidad será evaluada con base en la naturaleza del comportamiento ilegal, al nivel de participación e intención, a la existencia de algún motivo que conlleve discriminación y a cualquier tipo de abuso de poder (Corte Penal Internacional, 2016: párrafo 43).

Finalmente, el tercer criterio para la selección de casos se basa en las acusaciones aplicables al caso en particular. En este sentido, señala la Fiscalía que los cargos elegidos pretenden no sólo buscar que los crímenes atroces no queden impunes, sino también que las acusaciones elegidas constituyan una muestra representativa de los tipos de victimización y de las comunidades afectadas por dichos crímenes. En un acto novedoso, la Oficina Fiscal señala que pondrá especial atención a los crímenes que han sido especialmente desatendidos por la Corte, tales como crímenes que afectan a niños, violaciones y otros delitos sexuales, ataques contra la cultura, religión u objetos históricos y protegidos, y crímenes cometidos por fuerzas humanitarias de paz (Corte Penal Internacional, 2016: párrafo 46).

\section{¿Se amplía la competencia de la Corte Penal Internacional a delitos medioambientales?}

La prensa y el mundo medioambiental reaccionó rápidamente al documento de priorización planteado por la Fiscalía señalando que con esto se estaría generando una importante transformación en la competencia de la Corte ${ }^{8}$, pues la destruc-

7. Véase, además, Naciones Unidas (1998), artículos 8.2.b.ix y 8.2.e.iv.

8. Véase, por ejemplo, el artículo de John Vidal y Owen Bowcott publicado en The Guardian el 15 de septiembre de 2016, disponible en http://bit.ly/2cdfv6E; o de Chris Arsenault, publicado por Thomson 
ción medioambiental podría ser catalogada como un crimen de lesa humanidad 9 y que los directores de empresas podrían ser acusados ante la Corte por delitos medioambientales ${ }^{10}$.

El impacto en las organizaciones ambientalistas sobre esta nueva focalización de la Corte tiene su fundamento en los párrafos 7,40 y 41 del documento de priorización. El párrafo 7 señala que la Corte respetará y fomentará la jurisdicción local actuando como un sistema complementario de justicia penal. En este sentido, señala que cooperará con los Estados para investigar y perseguir a los individuos que hayan cometido o hayan facilitado la comisión de los delitos expresados en el Estatuto de Roma. Además, señala que pone a disposición de los Estados su asistencia técnica y cooperación para perseguir crímenes reconocidos bajo la jurisdicción nacional, tales como la explotación ilegal de recursos naturales, el tráfico de armas, el tráfico de personas, el terrorismo, crímenes financieros, desalojos forzosos o la destrucción del medioambiente (Corte Penal Internacional, 2016: párrafo 7). El párrafo 40 consagra la forma de la comisión de los crímenes, pues señala que se priorizarán, dentro de otras, aquellas acciones que se cometan con el objeto de o que resulten en la destrucción del medioambiente. Por último, el párrafo 41 trata sobre los impactos de los crímenes señalando que la Fiscalía pondrá especial atención a perseguir los crímenes del Estatuto de Roma, cometidos por o que resulten de, entre otros, la destrucción del medioambiente, la explotación ilegal de los recursos naturales o la desposesión ilegal de tierras (Corte Penal Internacional, 2016: párrafo 41).

Cabe señalar que ni la ayuda técnica que fortalece la complementariedad, ni la especial atención a crímenes medioambientales en su forma o resultado, generan un cambio en la competencia de la Corte. Ella continúa sujeta a los crímenes más graves para la comunidad internacional en su conjunto, esto es: genocidio, crímenes de lesa humanidad, crímenes de guerra y el crimen de agresión. La Oficina del Fiscal es enfática en señalar que los policy papers no son más que documentos que permiten dar a conocer de manera transparente la forma en que la Fiscalía selecciona los casos a ser investigados, pero que en ningún caso constituyen derechos para las partes (Corte Penal Internacional, 2016: párrafos 4-5). A su vez, el deber de cooperar con los Estados Parte en la investigación de crímenes es una facultad de la Corte que ya estaba expresada en el artículo 93.10 del Estatuto de Roma.

Lo novedoso recae en el énfasis que pondría la Fiscalía en la selección de casos de que han sido poco tratados por la Corte, dentro de los cuales se encuentran los

Reuters Foundation el 15 de septiembre de 2016, disponible en http://tmsnrt.rs/2d2RWuo.

9. Por ejemplo, el artículo de Adam Taylor publicado en The Washington Post el 16 de septiembre de 2016, disponible en http://wapo.st/2cDikwQ.

10. Así indica el artículo de Shehab Khan, publicado en The Independent el 19 de septiembre de 2016, disponible en http://ind.pn/2 coxBRS. 
delitos medioambientales. La pregunta es si de por sí esto es de importante para la persecución de delitos medioambientales a nivel internacional.

\section{Crímenes de lesa humanidad: Crímenes contra el medioambiente y contra defensores}

La nueva política de selección de casos puede resultar importante para el campo del derecho internacional de derechos humanos, toda vez que ahora la Corte puede considerar relevantes actos o elementos del contexto para determinar ciertos crímenes de lesa humanidad, esto no sin las limitaciones que la propia jurisdicción de la Corte se ha autoimpuesto.

Existe extensa evidencia en la doctrina y en la práctica sobre la apropiación indebida de tierras, explotación de recursos naturales y contaminación del medioambiente que afecta principalmente a pueblos indígenas o grupos desaventajados. La Federación Internacional de Derechos Humanos ha reconocido que los defensores de derechos humanos son constantemente amenazados, difamados, torturados y asesinados por defender el medioambiente y la tierra, un fenómeno global que se da particularmente en zonas con altos niveles de extractivismo y proyectos de desarrollo (FIDI y OMCT, 2014). La ONG Global Witness ha llegado a similares conclusiones al señalar que el 2015 «fue el peor de la historia en lo que respecta al asesinato de defensores de la tierra y el medioambiente», con 185 asesinatos en 16 países, un aumento de $59 \%$ respecto del 2014 (Global Witness, 2016: 4). Dicha preocupación es también compartida por la organización Global Diligence, que ha reconocido que la apropiación indebida de tierras y los consecuentes desplazamientos forzados son hoy en día uno de los mayores problemas de derechos humanos a nivel global, pues genera efectos dañinos principalmente en los países más pobres. Es a partir de dicha situación que el año 2014 presentaron una comunicación individual para que la Corte investigara el desplazamiento forzado de cerca de 830.000 personas (principalmente minorías indígenas) en Camboya ${ }^{11}$. La Corte tendría al menos dos opciones para que ello ocurra.

La primera vía sería mediante el artículo 8.2.b.iv del Estatuto de Roma, que consagra la destrucción ambiental como una forma de crimen de guerra ${ }^{12}$. Para que la

11. Así indica el comunicado de Global Diligence del 15 de septiembre de 2016, disponible en http://bit. ly/2vDikns. Dicha comunicación busca responsabilizar a altos miembros del gobierno de Camboya, sus fuerzas de seguridad y líderes de negocios conectados con el gobierno que llevaron a cabo un ataque a la población civil con un doble objetivo, el autoenriquecimiento y la conservación del poder. Parte de los crímenes denunciados incluyen el asesinato, el traslado forzoso, la prisión ilegal y otros actos inhumanos.

12. Estatuto de Roma, artículo 8.2.b.iv: «Lanzar un ataque intencionalmente, a sabiendas de que causará pérdidas incidentales de vidas, lesiones a civiles o daños a bienes de carácter civil o daños extensos, duraderos y graves al medioambiente natural que serían manifiestamente excesivos en relación con la ventaja militar concreta y directa de conjunto que se prevea». 
Oficina del Fiscal pueda perseguir dichos crímenes, debe generar suficiente evidencia respecto a que: i) dicho acto haya sido intencional; ii) el daño causado haya sido de largo plazo, severo o generalizado, y iii) la existencia de desproporción en el umbral de responsabilidad. En este sentido, los requisitos de intencionalidad, daño y desproporción generan una barrera de entrada para que la Fiscalía pueda siquiera comenzar a aplicar los criterios establecidos en la nueva política de selección y priorización de casos. Tanto así que el artículo 8.2.b.iv del Estatuto de Roma no ha sido nunca invocado en el contexto de la Corte (Anton, 2016). La opción de invocar la destrucción ambiental como crimen de guerra estaría puesta entonces en casos decididos por entidades distintas a la Corte ${ }^{13}$.

A estas trabas de entrada para que la Fiscalía investigue ciertos casos se le debe agregar un problema adicional: la responsabilidad de parte importante de estos crímenes recae en agentes no estatales, generalmente en empresas multinacionales. La pregunta es si la Corte tiene o no la capacidad para perseguir dicha responsabilidad, pues en un mundo de economías globalizadas y con escasez de control estatal, se vuelve fundamental la necesidad del control internacional ante eventuales violaciones de derechos humanos por parte de las empresas multinacionales, en especial si se toma también en consideración el importante peso que tienen en la adopción estatal de tratados internacionales ${ }^{14}$.

A pesar de las analizadas barreras, existiría, en principio, una solución jurídica de más fácil acceso. El artículo 7 del Estatuto de Roma define los crímenes de lesa humanidad como:

Cualquiera de los actos siguientes cuando se cometa como parte de un ataque generalizado o sistemático contra una población civil y con conocimiento de dicho ataque $[\ldots]$ h) persecución de un grupo o colectividad con identidad propia fundada en motivos políticos, raciales, nacionales, étnicos, culturales, religiosos, de género definido en el párrafo 3 , u otros motivos universalmente reconocidos como inaceptables con arreglo al derecho internacional, en conexión con cualquier acto mencionado en el presente párrafo o con cualquier crimen de la competencia de la Corte.

Esta definición no requiere que el acto sea llevado a cabo en un contexto de guerra, sino que sea un «ataque generalizado o sistemático contra una población civil», la que puede resultar o no de la violencia física, sin excluir los denominados delitos cometidos contra los defensores de tierras o del medioambiente. Ello puede resultar en una importante herramienta de defensa del derecho internacional de los derechos humanos, por lo que la nueva focalización de la Fiscalía podría perfectamente adop-

13. Véanse los ejemplos puestos en Jacobsson (2015; 2016).

14. Véase, por ejemplo, Gowlland-Debbas (2013). En materia de empresas y derechos humanos, véase Alston (2005) y De Schutter (2006). 
tar esta estrategia para terminar con la impunidad que actualmente existe en materia de crímenes graves en un contexto de destrucción medioambiental y de persecución a defensores del medioambiente.

\section{Algunas consideraciones finales}

Los crímenes contra el medioambiente y contra defensores de derechos humanos golpean principalmente a países que basan sus economías en el extractivismo o que se encuentran en desarrollo de grandes obras de infraestructura. La focalización presentada por la Fiscalía de la Corte Penal Internacional es pues una mirada directa a los sucesos que ocurren en el sur del planeta. Si bien gran parte del foco de la Corte ha estado puesto en el continente africano, esta nueva focalización abre las puertas a América Latina. Dicha afirmación se vuelve evidente al observar las cifras de conflictos socioambientales a nivel global, toda vez que un $37 \%$ de dichos conflictos están concentrados en territorio americano ${ }^{15}$, cifra que es aún más preocupante si se considera que el $66 \%$ de los casos de asesinatos originados por la defensa del medioambiente o de las tierras, reportados por Global Witness entre 2010 y 2015, ocurrieron en territorio latinoamericano (Global Witness, 2016: 9). La pregunta que habrá que analizar a la luz de la implementación del documento de priorización es hasta qué punto este nuevo foco presentado por la Corte colaborará en disminuir la impunidad existente en la gran mayoría de estos casos.

Para contribuir a dicho análisis, en este trabajo se ha analizado tanto la metodología de selección y priorización de casos elaborado por la Fiscalía, como su intención de tratar casos en materia de violaciones de derechos ambientales y de persecución contra defensores del medioambiente. Un análisis crítico de dicho documento lleva a concluir que si bien la intención de la Fiscalía reconoce las graves violaciones a derechos humanos que ocurren en un contexto de defensa del medioambiente y la potencial responsabilidad penal de ciertos agentes, las barreras de entrada para seleccionar casos hacen difícil su aplicación práctica. Y si bien existe cierta posibilidad de utilizar el artículo 7 del Estatuto de Roma para perseguir dichos delitos, la comunidad internacional debiese reaccionar con mayor vehemencia frente a las violaciones a derechos humanos y derechos del medioambiente.

\section{Referencias}

Alston, Philip (2005). «The 'not-a-cat' syndrome: Can the international human rights regime accommodate non-State actors?». En Philip Alston (editor), NonState actors and Human Rights (pp. 3-36). Oxford: Oxford University Press.

15. Véase el mapa interactivo «Environmental Justice Atlas», disponible en https://ejatlas.org/. 
Anton, Don (2016). «Adding a green focus: The Office of the Prosecutor of the International Criminal Court highlights the 'environment' in case selection and priorisation». Australian Environment Review, 31 (1): 1-13. Disponible en https://ssrn. com/abstract $=2879775$.

Corte Penal Internacional (2007). «Policy paper on the interests of justice». Disponible en http://bit.ly/2vJWDT6.

-. (2013a). «Código de conducta de la Fiscalía». OTP 2013/o24322. Disponible en http://bit.ly/2v1K2xh.

-. (2013b). «Policy paper on preliminary examinations». Disponible en http://bit. ly/2eOqVQD.

-. (2016). «Policy paper on case selection and prioritisation». Disponible en http:// bit.ly/2uYtHZV.

De Schutter, Olivier (2006). «The challenge of imposing human rights norms on corporate actors». En Olivier de Schutter (editor), Transnational corporations and human rights (pp. 1-40). Oxford: Hart Publishing.

Drumbl, Mark (2000). «International human rights, international humanitarian law, and environmental security: Can the International Criminal Court bridge the gaps?». ILSA Journal of International \& Comparative Law, 5 (2): 1-27. DOI: $10.2139 /$ ssrn.263443.

FIDH y OMCT (2014). «No tenemos miedo»: Defensores del derecho a la tierra. Atacados por enfrentar el desarrollo desenfrenado. París.

Global Witness (2016). En terreno peligroso. Londres: Global Witness. Disponible en http://bit.ly/28Jbse8.

Gowland-Debbas, Vera (editor) (2013). Multilateral treaty-making. The current status of challenges to and reforms needed in the international legislative process. Dordrecht: Springer.

JACOBsson, Marie (2015). «Segundo informe sobre la protección del medio ambiente en relación con los conflictos armados». A/CN.4/685. Disponible en http://bit. ly/2gY2Ya4.

-. (2016). «Tercer informe sobre la protección del medio ambiente en relación con los conflictos armados». A/CN.4/70o. Disponible en http://bit.ly/2uTVZUR.

Naciones Unidas (1998). «Estatuto de Roma de la Corte Penal Internacional». 2187 UNTS 90, 37 ILM 1002. Disponible en http://bit.ly/2uv13g6.

Organización de Estados Americanos (1988). «Protocolo adicional a la Convención Americana sobre Derechos Humanos en materia de derechos económicos, sociales y culturales». Disponible en http://bit.ly/2q3FKn1.

SAnds, Philippe y Jaqueline PeEL (2012). Principles of internatinal environmental law. Cambridge: Cambridge University Press.

SKogly, Sigrun (2001). «Crimes against humanity revisited: Is there a role for econo- 
mic and social rights?». The International Journal of Human Rights, 5 (1): 58-80. DOI: $10.1080 / 714003700$.

\section{Sobre el autor}

Sebastián Smart es licenciado en Derecho de la Universidad Católica de Chile, magíster en Derechos Humanos de la University College of London y candidato a doctor en la misma casa de estudios. Es diplomado en Descentralización y Desarrollo Local de la Universidad Alberto Hurtado. Ha trabajado en la ONG Techo en Chile, Haití y el Reino Unido. Además, ha sido consultor de diversas organizaciones internacionales, tales como London Mining Network y Colombian Caravana, y ha colaborado con el estudio jurídico Deighton, Pierce \& Glynn en casos de derechos humanos en el Reino Unido.Su correo electrónico es juan.smart.12@ucl.ac.uk. 
